Article

\title{
Assessment of Pharmacists' Knowledge and Competence Regarding Anti-Tobacco Counseling
}

\section{Justyna Dymek * and Agnieszka Skowron}

The Department of Social Pharmacy, Faculty of Pharmacy, Jagiellonian University Medical College, Medyczna 9 Street, Kraków 30-688, Poland; E-Mail: askowron@cm-uj.krakow.pl

* Author to whom correspondence should be addressed; E-Mail: jdymek@cm-uj.krakow.pl Tel.: +48-12-620-5820; Fax: +48-12-620-5519.

Received: 1 August 2013; in revised form: 4 November 2013 / Accepted: 20 November 2013 / Published: 28 November 2013

\begin{abstract}
The aim of the study was to assess Polish community pharmacists' knowledge about the health consequences of smoking and the abilities they need in professional advice-giving during the smoking cessation process. Therefore, we use a self-answered questionnaire to assess pharmacists' knowledge about the health consequences of smoking and his/her abilities in NRT advice-giving. In total, the pharmacists could earn 20 points, 14 in the knowledge section and 6 in the abilities section. One hundred and nine pharmacists from community pharmacies were included, 87 of whom were women (79\%). The average age of respondents was 38 years (24-72). The mean knowledge rating of pharmacists regarding the health risk factors connected with smoking was 7.7 points $(\mathrm{SD}=2.2)$, the maximum was 14 . None of the respondents obtained the maximum possible score in the test. Only $2.7 \%$ of pharmacists correctly identified all four factors important in selecting the form of NRT. Analysis showed that pharmacists' knowledge about tobacco dependence and tobacco-related diseases is insufficient for an effective tobacco control interventions. It seems necessary to undertake systematic training to improve their knowledge about nicotine addiction and abilities in NRT and smoking cessation advice-giving.
\end{abstract}

Keywords: pharmacists' counseling; smoking cessation; health education; tobacco smoking 


\section{Introduction}

WHO has summarized the health consequences of smoking and passive smoking and indicates smoking as a serious problem all over the world [1,2]. Smoking and passive smoking are associated with many diseases and consequent economic problems for society [3]. The direct costs of smoking are, among others, costs connected to the treatment of smoking-related diseases such as medications and hospitalization and the indirect costs such as productivity losses caused by work absence and untimely deaths [4]. European countries spend lots of money on the treatment of smoking-related diseases such as chronic obstructive pulmonary diseases (COPD), coronary disease, lung cancer, brain stroke, oral and larynx cancer, peripheral atherosclerosis [5]. The number of deaths caused by smoking in the population under 65 still remains high compared to Western European countries [6,7]. In those societies, one-fifth of young people aged 15-24 smoke cigarettes, more than $12 \%$ of Polish women do not quit smoking during pregnancy [8].

The MPOWER (Monitor, Protect, Offer, Warn, Enforce, Raise) report from 2008 (the first WHO report concerning the global situation of smoking cessation and the impact of anti-smoking interventions) showed creating non-smoking zones, anti-smoking education and supporting people, who wants to give up smoking to be the best anti-smoking activity. The report indicated community pharmacists as a group of health professionals who can have an essential influence on health behaviors and smoking cessation decisions [2,9].

Pharmacists can successfully lead anti-smoking programs and promote non-smoking behaviors. Face-to-face contact with patients give them an opportunity to start health education and support smoking-cessation [2]. Pharmacists should counsel and provide patients' care during the smoking cessation process to improve their success rate and maintain abstinence [10].

Community pharmacists are one of the most easily accessible health professionals. This makes them extremely useful in promoting non-smoking. They should focus on increasing the knowledge about smoking consequences and encouraging customers towards smoking cessation. Community pharmacists have an opportunity to influence a large group of healthy people who do not visit their physicians. In addition, the community pharmacies, due to convenient opening hours and high density, are one of the best places to implement health education programs. Patients do not need to make an appointment and pharmacists can usually find time for a short anti-smoking counseling session. Pharmacists are professionals, who should be obliged to inform, counsel patients and provide pharmaceutical care [11-17]. Even if a pharmacist does not have enough knowledge to collaborate with a patient during the smoking cessation process, he or she should at least ask about smoking habits or give an information leaflet about smoking health consequences or direct him or her to another health professional, who will support the patient [11].

The EuroPharm Report indicates the pharmacist to be a member of medical staff, who is able to contact other medical staff members. This helps patients to get better health care [17]. About 20,000 pharmacists work in almost 12,000 community pharmacies in Poland. One community pharmacy serves about 3,500 people. Community pharmacies are financed from the margin of medication, so dispensing medication is their main professional activity. Although pharmaceutical care services are not currently remunerated in Poland, a pharmacist could be involved in non-smoking 
promotion (education about consequences of smoking, including passive smoking) and Nicotine Replacement Therapy (NRT) management.

The objective of the study was to assess community pharmacists' knowledge about the health consequences of smoking and their abilities needed in professional advice-giving during the smoking cessation process.

\section{Methods}

The study involved a survey of community pharmacists using a self-completion questionnaire to assess the knowledge and abilities of pharmacists. The questionnaire consisted of 18 questions including open-ended and closed questions, with single or multiple answers. Seven questions in total were used to assess pharmacists' knowledge about the health consequences of smoking (five questions) and NRT advice-giving. The pharmacists' attitudes towards smoking and the self-assessment of their knowledge were also assessed (six questions). Five separate questions were dedicated to pharmacists, who were smokers. The questions assessing knowledge and abilities was scored. If pharmacists responded to all questions correctly, they could get 20 points in total, 14 in the knowledge section and 6 in the abilities and self-assessment section.

The study is a part of the "Community pharmacy smoking cessation project", which was approved by the local Bioethical Board.

Descriptive statistics were used for all study variables. Frequencies, mean, mode, and standard deviation were used to determinate demographics and level of knowledge and abilities in each category. The t-student statistics, analysis of variance and chi-square test were used where appropriate for comparing differences across men and women.

A survey was conducted between June and October 2011 among pharmacists working in community pharmacies in six southwestern provinces of Poland. The respondents were recruited to the study during the postgraduate continuous trainings.

\section{Results and Discussion}

The questionnaire was filled out by 109 pharmacists, 87 of whoom were women (79\%). The average age of respondents was 38 years (24-72). Among the respondents, 10 people (including 9 women) declared smoking. The pharmacists' mean knowledge regarding the consequences of smoking was 7.7 points $(\mathrm{SD}=2.2)$, the maximum was 14 . There were no significant differences in knowledge between smokers and non-smokers. People who correctly answered the question $(71.6 \%)$ "Can the application of nicotine lead to severe psychological and physical dependence" had better knowledge then the others: 7.9 points ( $\mathrm{SD}=2.2)$ compared to 7 points $(\mathrm{SD}=2.2)$, respectively $(p<0.04)$.

Among the diseases caused by smoking, most pharmacists identified chronic bronchitis $(\mathrm{n}=106)$, larynx $(n=105)$ and low birth weight infants $(n=105)$. The least frequently identified were cervical cancer $(n=23)$ and breast cancer $(n=25)$. Other diseases identified approximately $1 / 3$ of the respondents, the detailed results are presented in Table 1. Lung cancer was purposely omitted in the questionnaire as it is commonly associated with smoking cigarettes. 
Only $12.8 \%$ responders were able to indicate the number of carcinogenic substances in tobacco smoke. Only 7\% pharmacists correctly named three carcinogens released in tobacco smoke. Forty-five percent of answers did not identify any of the carcinogens released in tobacco smoke.

Table 1. Distribution of the answers on the questions concerning diseases caused by smoking.

\begin{tabular}{lcc}
\hline Disease & n & $\mathbf{\%}$ \\
\hline Larynx cancer & 105 & 96.3 \\
Bladder cancer & 38 & 34.9 \\
Breast cancer & 25 & 22.9 \\
Cervix of uterus cancer (Cervical cancer) & 23 & 21.1 \\
Peripheral vessels diseases & 100 & 91.7 \\
Chronic bronchiteritis & 106 & 97.3 \\
Osteoporosis & 35 & 32.1 \\
Low birth weight & 105 & 96.3 \\
\hline
\end{tabular}

An evaluation of the pharmacist's ability to select dose and formulation of NRT was undertaken. Its aim was to identify whether pharmacists are able to recognize patient and tobacco related factors, which should be considered when selecting the form and dose of NRT. We evaluated only the pharmacists' knowledge about the proper dose selection and we were not able to assess their skills during the counseling process. Instead, we focused on abilities for potential NRT advice-giving. Only $2.7 \%$ of pharmacists correctly identified all four factors important in selecting the form of NRT. These were the parameters: the time interval between waking up and smoking the first cigarette, patient preference, previous attempts to gain weight when quitting smoking and the presence of other diseases. A clear majority of respondents correctly identified the first of these factors $(n=83,76.2 \%)$, the number of smoked cigarettes per day and the time interval between waking up and smoking the first cigarette is essential to choose a right initial dose. Over $25 \%$ of pharmacists identified both of these factors, and 5\% did not indicate any. The details are shown in Table 2.

Table 2. Knowledge about form and dose of Nicotine Replacement Therapy (NRT) selection.

\begin{tabular}{lcc}
\hline \multicolumn{1}{c}{ Factors that determine the choice of NRT } & n & $\%$ \\
\hline Factors which should be considered in form of NRT selection & & \\
\hline The period from waking to first cigarette & 83 & 76.2 \\
Patient preference & 77 & 70.6 \\
Increase in body weight during previous attempts to quit smoking & 13 & 11.9 \\
The presence of other diseases & 41 & 37.6 \\
The average number of identified factors (SD) & 1.96 & 0.9 \\
\hline Factors which should be considered in dose of NRT selection & & \\
\hline Number of cigarettes smoked & 102 & 93.6 \\
The period from waking to first cigarette & 30 & 27.5 \\
The average number of identified factors (SD) & 1.2 & 0.5 \\
\hline
\end{tabular}

None of the respondents obtained the maximum possible score in the test of knowledge about smoking consequences and the rules for selection of NRT. We did not observe any difference in knowledge between smokers and non-smokers. The personal perception about their own level of 
competence in this area does not correlate with better knowledge in the test score. Detailed information on the general knowledge compared in different groups of respondents is presented in Table 3.

Table 3. The level of general knowledge about smoking consequences and NRT management in different groups of respondents.

\section{Respondents' group}

\begin{tabular}{ll}
\hline I have sufficient competence to provide advice & $11.4(2.8)^{*}$ \\
I have insufficient competence to give advice & $10.3(3.2)^{*}$ \\
\hline smokers & $10.9(1.7)^{*}$ \\
non-smokers & $11.2(2.9)^{*}$ \\
\hline Total & $11.1(2.8)$ \\
\hline \multicolumn{2}{c}{$* p>0.05$, t-student test. }
\end{tabular}

The majority of pharmacists declared that their knowledge about health consequences of smoking comes from undergraduate courses $(n=70,64 \%)$, about $37 \%$ learned about it at post-graduate courses $(\mathrm{n}=40)$ and $46 \%$ learned on their own $(\mathrm{n}=50)$, seven people $(6.4 \%)$ admitted they did not have any knowledge about this subject.

Almost all responders $(n=104,95.4 \%)$ said they encourage their patients to quit smoking. Surprisingly almost 29 pharmacists claimed they do not pay attention, whether someone smokes in their presence. The main reason for this type of behavior is indifference $(n=15,13.8 \%)$ or a feeling that "I feel awkward to point out someone's bad behavior" $(\mathrm{n}=14,12.8 \%)$, see Table 4.

Table 4. The attitude of pharmacists towards smokers.

\begin{tabular}{clrr}
\hline \multicolumn{2}{c}{ Encouraging patients to stop smoking } & $\begin{array}{r}\text { Yes } \\
\text { n, \% }\end{array}$ & $\begin{array}{c}\text { No } \\
\text { Do you allow people to smoke in your presence }\end{array}$ \\
\hline \multicolumn{2}{c}{ The reason } & & \\
\hline \multirow{2}{*}{ I agree } & "I do not care" & $13(11.9)$ & $2(1.8)$ \\
& "I feel awkward to point out someone's bad behavior" & $13(11.9)$ & $1(0.9)$ \\
\hline \multirow{2}{*}{ I disagree } & "Smoke is harmful" & $48(44.0)$ & - \\
& "the room filled in smoke is unpleasant" & $30(27.5)$ & $2(1.8)$ \\
\hline
\end{tabular}

In our study, pharmacists indicated the number of cigarettes smoked daily and the time interval between waking up and the first cigarette smoked as the most important factors, which should be considered in the selection of doses of NRT. More than $93 \%$ of respondents correctly indicated the first one and only $27.5 \%$ pointed the second one. Pharmacists correctly pointed about half of the factors important for the form and dose selection of NRT. Analysis showed that pharmacists' knowledge about tobacco dependence and tobacco-related diseases could be insufficient to provide effective tobacco control interventions. 
Pharmacists correctly answered about 11 (out of 20) questions concerning the health consequences of smoking. They did not recognize diseases caused by smoking and could not correctly point three carcinogens from tobacco smoke.

It seems necessary to undertake systematic training to improve their knowledge about nicotine addiction and NRT management. The results of previous studies showed that professional training increases pharmacists' awareness, and consequently improves the quality of advice-giving in the battle against tobacco addiction [9].

Worldwide studies proved that in the process of smoking cessation, the pharmacists' role is not only selecting the form and dose of NRT, but also motivating patients. Regular pharmacist-patient meetings during the smoking cessation process increase the chance of success [12]. Therefore, as pointed out, if the awareness of the pharmacists regarding their health professional role changed, it might increase their professional satisfaction [9]. The future economic benefits are an additional argument for raising pharmacists' involvement in health promotion activities. Despite the availability of NRT also in non-pharmacy sales, the significant proportion of smokers also come to the pharmacy because they are looking for advice [9].

Our responders were pharmacists who participated in post-graduate courses dedicated to health promotion, so it is possible that it was a group of pharmacists who were interested in expanding their professional roles for smoking customers. The health promotion courses are not included in curricula for pharmacy students in Poland. It is possible that such courses could be done as optional courses, but there is no evidence as to how often pharmacy students in Poland are taught about the role of pharmacists in health promotion. Our university offers such courses for all pharmacists in our region. Our teaching methods are focused on expanding the abilities of pharmacists who want to work in future with customers who smoke. Usually, at our health promotion course, we have about 30-40 participants each year. This is a small part of all pharmacists in our region (we have about 2,500 pharmacists in community pharmacies in the Malopolska region). In the previous year we assessed the quality in smoking cessation counseling among community pharmacists in Cracow, which showed that most of the community pharmacists were not able to provide the proper smoking cessation advice-giving [18]. This was one of the reasons for creating the continuing education courses in health promotion. We were not able to assess the level of knowledge of pharmacists, who were not interested in expanding their professional role in health promotion and have not participated in health promotion courses. Such comparison could be the aim of another study.

The results of our study and its conclusion are limited to the situation in Malopolska region. However, we may predict that, in other regions in Poland, the situation could be the same or worse. Pharmacy students do not have a lot of opportunities to learn about health promotion, due to lack of such types of courses in Pharmacy Curricula in Poland.

\section{Conclusions}

It is worth considering reconstituting the role of community pharmacists in health promotion and prevention programs in Poland. Their active role in the smoking cessation process may bring financial benefits and improve the health of the society. The pharmaceutical associations should focus on developing guidelines and standards of anti-smoking intervention, as research has showed that this is 
the best way to encourage the various medical professional groups, including pharmacists, to start such professional activity.

\section{Conflicts of Interest}

The authors declare no conflict of interest.

\section{References and Notes}

1. World Health Organization (WHO). The World Health Report 2002: Reducing Risks, Promoting Healthy Life; WHO: Geneva, Switzerland, 2002.

2. World Health Organization (WHO). WHO Report on the Global Tobacco Epidemic, 2008: The MPOWER Package; WHO: Geneva, Sweden, 2008.

3. Alzoubi, K.H.; Azab, M.; Khabour, O.F.; Al-Shamaila, A.W.; Ayoub, N.M.; Al-Omiri, M.K.; Al-Nasser, A.D.; Mhaidat, N.M.; Al-Azzam, S.I. Smoking-cessation practice guidelines: Awareness and implementation among medical teams. Int. J. Pharm. Pract. 2010, 18, 93-99.

4. Rascati, K.L. Essentials of Pharmacoeconomics; Lippincott Williams \& Wilkins: Philadelphia, PA, USA, 2009.

5. Jabłecka, A.; Korzeniowska, K. Smoking addiction-health and economic problem. Przeglad Lekarski 2011, 68, 998-999.

6. Zatoński, W.A.; HEM Project Team. Epidemiological analysis of health situation development in Europe and its causes until 1990. Ann. Agric. Environ. Med. 2011, 18, 194-202.

7. Zatoński, W.; Zatoński, M.; Przewoźniak, K. Health improvement in Poland is contingent on continued extensive tobacco control measures. Ann. Agric. Environ. Med. 2013, 20, 405-411.

8. Wojtyła, A.; Goździewska, M.; Paprzycki, P.; Biliński, P. Tobacco-related Foetal Origin of Adult Diseases Hypothesis - population studies in Poland. Ann. Agric. Environ. Med. 2012, 19, 117-128.

9. Kurko, T.; Linden, K.; Pietilä, K.; Sandström, P.; Airaksinen, M. Community pharmacists' involvement in smoking cessation: Familiarity and implementation of the National smoking cessation guideline in Finland. BMC Public Health. 2010, 10, doi:10.1186/1471-2458-10-444.

10. Small, R.E.; James, C.W. Smoking cessation: Pharmacists helping patients kick the habit. J. Am. Pharm. Assoc. 2003, 43, 26-27.

11. Hudmon, K.S. The pharmacist's role in tobacco cessation: Overview and introduction to the series. Am. J. Health Syst. Pharm. 2007, 64, 1434-1436.

12. Costello, M.J.; Sproule, B.; Victor, J.C.; Leatherdale, S.T.; Zawertailo, L.; Selby, P. Effectiveness of pharmacist counseling combined with nicotine replacement therapy: A pragmatic randomized trial with 6,987 smokers. Cancer Causes Control 2011, 22, 167-180.

13. The act of April 1991 on pharmaceutical chamber. Available online: http://isap.sejm.gov.pl/ SearchServlet (accessed on 1 August 2013).

14. Panas, M.; Brandys, J. Preparation of a programme entitled "The role of pharmacists in providing support for nicotine replacement therapy in public pharmacies. Przeglad Lekarski 2008, 65, 719-723. 
15. Laliberté, M.C.; Perreault, S.; Damestoy, N.; Lalonde, L. Ideal and actual involvement of community pharmacists in health promotion and prevention: A cross-sectional study in Quebec, Canada. BMC Public Health. 2012, 12, doi:10.1186/1471-2458-12-192.

16. Hoch, M.A.; Hudmon, K.S.; Lee, L.; Cupp, R.; Aragon, L.; Tyree, R.A.; Corelli, R.L. Pharmacists' perceptions of participation in a community pharmacy-based nicotine replacement therapy distribution program. J. Community Health 2012, 37, 848-854.

17. Pharmacists and action of tobacco. Available online: http://www.fip.org/files/fip/tobacco/ publications/Pharmacists\%20and\%20Action\%20on\%20Tobacco.pdf (accessed on 1 August 2013).

18. Brandys, J.; Panas, M.; Skowron, A.; Urbaczka, A. Assessment of the effectiveness of pharmacists' activities in treatment of tobacco-addicted patients in the context of pharmacists' counselling in Cracow's pharmacies. Przeglad Lekarski 2009, 66, 836-840.

(C) 2013 by the authors; licensee MDPI, Basel, Switzerland. This article is an open access article distributed under the terms and conditions of the Creative Commons Attribution license (http://creativecommons.org/licenses/by/3.0/). 